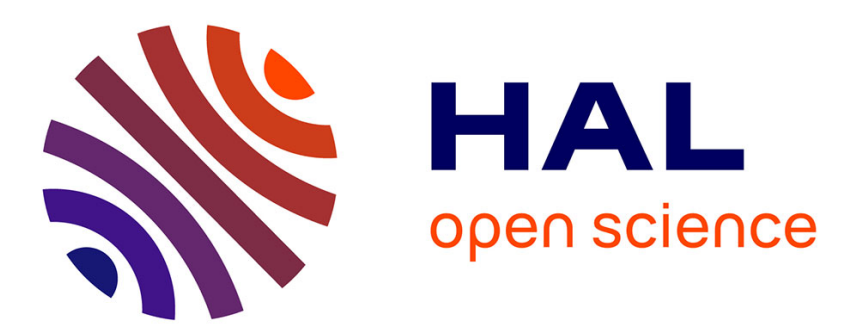

\title{
A study of the effect of the transition curve in the coupling elements between the carbody and the bogie
}

\author{
Ronald Martinod, German R Betancur, Leonel Castañeda, Jose F Osorio
}

\section{To cite this version:}

Ronald Martinod, German R Betancur, Leonel Castañeda, Jose F Osorio. A study of the effect of the transition curve in the coupling elements between the carbody and the bogie. International Journal of Heavy Vehicle Systems, inPress, 21 (4), pp.351 - 363. 10.1504/IJHVS.2014.068113 . hal-02182075

\section{HAL Id: hal-02182075 \\ https://hal.science/hal-02182075}

Submitted on 12 Jul 2019

HAL is a multi-disciplinary open access archive for the deposit and dissemination of scientific research documents, whether they are published or not. The documents may come from teaching and research institutions in France or abroad, or from public or private research centers.
L'archive ouverte pluridisciplinaire HAL, est destinée au dépôt et à la diffusion de documents scientifiques de niveau recherche, publiés ou non, émanant des établissements d'enseignement et de recherche français ou étrangers, des laboratoires publics ou privés. 


\title{
A study of the effect of the transition curve in the coupling elements between the carbody and the bogie
}

\section{Ronald M. Martinod*, German R. Betancur, Jose F. Osorio and Leonel F. Castañeda}

\author{
Mechanical Engineering Department, \\ Universidad EAFIT, \\ Cra. 49 No. 7 Sur - 50, Medellín, Colombia \\ Email: rmartino@eafit.edu.c \\ Email: gbetanc4@eafit.edu.co \\ Email: josori29@eafit.edu.co \\ Email: lcasta@eafit.edu.co \\ ${ }^{*}$ Corresponding author
}

\begin{abstract}
This work describes an analysis of the effect of the transition curves in the coupling elements between the carbody and the bogie, by means of recorded variables under commercial operation conditions of a railway vehicle. A set of field tests are developed and applied to the railway system as a basis to validate a numerical model. The dataset is obtained from a numerical model based on the multi-body systems theory using a transient method. The study focuses on the dynamic evaluation of the vehicle to determine the transversal dynamic effect generated by the circulation in the transition curve sections, especially in curves with short radius. The work includes a case study of a passenger railway, and it is used to identify aspects of the railway system that could be improved by the operators, such as inspection routines, rail track design and elements subjected to considerable loads.
\end{abstract}

Keywords: bolster beam; multi-body theory; railway testing; transition curve track; railroad vehicle dynamic.

Reference to this paper should be made as follows: Martinod, R.M., Betancur, G.R., Osorio, J.F. and Castañeda, L.F. (2014) 'A study of the effect of the transition curve in the coupling elements between the carbody and the bogie', Int. J. Heavy Vehicle Systems, Vol. 21, No. 4, pp.351-363.

Biographical notes: Ronald M. Martinod obtained his MS from EAFIT University. His major research fields are dynamic modelling of railways and the non-linear analysis of vehicles.

German R. Betancur obtained his BS and MS in Engineering from EAFIT University. $\mathrm{He}$ is the co-investigator in the Research Group of Industrial Maintenance (GEMI), responsible for developing of dynamic tests to engineering systems such as vehicles, wind turbines and hydraulic generators.

Jose F. Osorio is an MS student in Engineering of EAFIT University.

Leonel F. Castañeda received his PhD from the University of Technology and Life Sciences in Bydgoszcz (Poland) and his MS from the University of Science and Technology of Krakow (Poland). He is a Professor of the 
Mechanical Engineering Department and coordinator of GEMI Research Group, technical diagnosis line. His research interests include topics related to mechanic vibration and technical diagnosis.

\section{Introduction}

Passenger trains have a two-stage suspension:

- primary - elements that connect the bogie to the axlebox

- secondary - elements that connect the carbody to the bogie.

The coupling between carbody and bogie has a structural element with two main functions:

- to provide structural stiffness to loads distribution

- to allow the connection to the bogie in the secondary suspension stage (Martinod et al., 2012a).

The coupling between carbody and bogie must, among other functions,

- allow the bogie to turn relative to the carbody on curved track

- provide additional control of lateral suspension inputs.

These problems have been solved by different alternatives depending on the rolling stock - traction or trailing, passenger or freight, medium or high speed. If the vehicle has such design that it experiences a period of unstable running with a speed lower than the vehicle running speed, then the addition of a yaw resistance torque is necessary, and also, if the deflection of the suspension is insufficient, a vertical flexibility in the carbody to the bogie is necessary (Castañeda et al., 2012; Orlova, 2006).

Existing designs of coupling between carbody and bogie point to obtain a configuration as simple as possible by means of a reduction of the quantity of parts, specifically, a reduction of the elements that possess coupling with friction surfaces. The designs are classified according to the typology of the coupling configuration (Spiryagin et al., 2014; Orlova, 2006):

- central plane plate

- spherical central supporting frame

- central bolster beam

- watt hinge

- pendulum hinge

- connection without beam.

The work focuses on studying the effects that the track sections, denominated as transition curve (TC), exercise on the coupling elements between carbody and bogie. The paper is supported by a set of numerical simulations based on the multi-body theory and a 
set of measurements on commercial operating conditions. The computational simulations of the non-linear dynamics of railway systems are composed of two elements (Shabana et al., 2008):

- the vehicle conformed by equations of motion that are formulated and solved from perturbations of the system

- the track geometrical definition.

These elements are addressed here.

\subsection{The vehicle}

The work focuses on trains that have a central bolster beam configuration-type, which is used with the objective of obtaining a connection without edge-contact and increasing the friction torque to resist the yaw of the bogie; the mass of the carbody is transmitted through the bolster beam and it can only turn relative to the bolster about a vertical axle (Orlova, 2006). The disadvantages of using this configuration include:

- the existence of clearances in longitudinal and lateral directions

- the design, which provides enough ride quality only for bogies having low lateral stiffness of secondary suspension stage.

The configuration is used widely in passenger trains - e.g. in the former USSR (Orlova, 2006).

\subsection{The track}

The dynamic behaviour of the vehicle depends on the geometry of the wheel and the rail. An efficient and systematic description of the geometry of the track is obtained by using a set of standard section types (Shabana et al., 2008):

- tangent track - straight

- $\quad$ circular curve $(C C)$ with constant radius $R$

- $T C_{i}$, entrance to $C C$ - spiral entrance tangent to the curve

- $T C_{f}$, exit of $C C$ - spiral exit tangent to the curve

- other section types - switch, crosslevel, etc.

The section types are used to describe the track design and to facilitate the development of the mathematical formulation of complex tracks.

Transition curve $(T C)$ is used when a circular curve joins the straight track or when a circular curve joins another track section, for smoothly compensating of the lateral acceleration on the vehicle as the radius of the track changes (Mundrey, 2010). To ensure traffic safety and provide comfort to passengers, cant is also introduced into the $T C$ to help offset lateral forces develop from the tilting plane (Shen et al., 2013). In $T C$, the curvature value, $1 / R$, gradually increases from $1 / R=0$ in straight track, to the curvature corresponding to the $C C$ value; the increment of the curvature has a linear relation, $s / L R=1 / r$, where $L$ is the length of the $T C$ section, $s$ is the distance away 
from the start point of the $T C$ and $1 / r$ is the curvature at that point distance away (Profillidis, 2014; Shen et al., 2013). In consequence, the curvature equation can be expressed as $\mathrm{d} \phi / \mathrm{d} s=1 / r$, where $T C$ can be defined through the parameter $\phi$, which describes a geometry corresponding to a clothoid (Euler spiral), half-sine or cubic parabola depending on the railway system (Profillidis, 2014; Shen et al., 2013). In the railway industry, the geometry of the track is defined by the following three variables (Shabana et al., 2008):

- projection, which defines the planar curve obtained by projecting the reference line on the horizontal plane

- development, which defines an elevation angle

- crosslevel, which defines a bank angle $\phi$ that represents the rotation of the profile frame about the tangent to the reference line.

\section{Description of the object of study}

The study is applied to passenger vehicles belonging to the mass railway vehicle fleet of Medellin city (Colombia), a railway system with 18 years of operation that has trains composed of two units each one with three coupled cars. The original equipment manufacturer of rolling stock was MAN, for the mechanical components, and Siemens for the electrical components. The vehicles are similar in geometry and design to the units ET420 train set, formerly operated by Deutsche Bahn, e.g., Munich S-Bahn (Martinod et al., 2012b). The total length of each unit of three cars is $68.5 \mathrm{~m}$; the end cars are powered, whereas the centre car is an unpowered trailer car. Each car possesses two bogies provided by two axle-wheel sets; each bogie has two suspension stages (Martinod et al., 2012a).

The distribution of the permanent track has three lines (A, B, C), which have been classified into three types of curved tracks according to the railway normative (International Union of Railways, 2005):

- short radius curve

- medium radius curve

- long radius curve (Table 1).

The curved tracks with lower $R$ have a bigger crosslevel value and a bigger twisting effect in the $T C$ owing to the bank angle $\phi$, therefore, the curved sections with a lower $R$ have a $T C$ section with higher perturbation on the vehicle, and then have a bigger dynamic effect over the train. As a consequence, the work focuses on the curved sections with lower radius $(250 \mathrm{~m}<R<400 \mathrm{~m})$.

The commercial tracks - Line A and Line B - have a set of curves with $R=300 \mathrm{~m}$, with a speed range $V=[62, \ldots, 80] \mathrm{km} / \mathrm{h}$. The curves have been classified according to the curve radius (see Table 2). 
Table 1 Track classification based on the railway normative

\begin{tabular}{lcccc}
\hline & & \multicolumn{3}{c}{ Curve length $(T C+C C)[\mathrm{m}]$} \\
\cline { 3 - 5 } Track classification & $R[\mathrm{~m}]$ & Line $A$ & Line $B$ & Line $C$ \\
\hline Short radius curve & $250<R<400$ & 8204.72 & 3610.73 & 142.29 \\
Medium curve radius & $400<R<600$ & 3932.98 & 398.93 & 0.00 \\
Long radius curve & $600<R$ & 5820.24 & 1131.63 & 1258.38 \\
\hline
\end{tabular}

Source: International Union of Railways (2005)

Table 2 Curved sections of permanent track with minimum radius

\begin{tabular}{|c|c|c|c|c|c|c|}
\hline \multirow[b]{2}{*}{$R[\mathrm{~m}]$} & \multirow[b]{2}{*}{ Line } & \multirow[b]{2}{*}{ Name } & \multirow[b]{2}{*}{$V[\mathrm{~km} / \mathrm{h}]$} & \multicolumn{2}{|c|}{ Section length $[\mathrm{m}]$} & \multirow[b]{2}{*}{ Crosslevel [mm] } \\
\hline & & & & $T C$ & $C C$ & \\
\hline \multirow[t]{14}{*}{300} & $\mathrm{~A}$ & $C 26$ & 64 & 055.00 & 088.97 & 161.11 \\
\hline & & $C 27$ & 80 & 106.50 & 105.36 & 251.73 \\
\hline & & C37 & 80 & 108.00 & 372.91 & 251.73 \\
\hline & & C44 & 80 & 58.96 & 040.05 & 251.73 \\
\hline & & $C 87$ & 80 & 120.00 & 184.04 & 251.73 \\
\hline & & $C 17$ & 80 & 120.00 & 112.17 & 251.73 \\
\hline & & $C 25$ & 62 & 053.23 & 073.43 & 151.20 \\
\hline & & C30 & 74 & 072.80 & 066.57 & 215.39 \\
\hline & & C32 & 80 & 105.64 & 142.43 & 251.73 \\
\hline & & C36 & 80 & 120.00 & 322.54 & 251.73 \\
\hline & B & $C 5^{\prime}$ & 80 & 105.00 & 120.00 & 251.73 \\
\hline & & $C 8^{\prime}$ & 80 & 120.00 & 123.00 & 251.73 \\
\hline & & $C 4^{\prime}$ & 80 & 119.26 & 119.26 & 251.73 \\
\hline & & C12' & 80 & 122.24 & 113.30 & 251.73 \\
\hline
\end{tabular}

\section{Development of the numerical model}

The dynamic simulations are practical sources of data and they are widely used to demonstrate running safety and acceptability of the dynamic behaviour of the vehicle (Evans and Berg, 2009). This dynamic is represented by a numerical model in which the accuracy is mainly affected by the model of wheel-rail contact and by the models of vehicle suspension components (Bruni et al., 2011; Di Gialleonardo et al., 2012). The developed numerical model represents a motor car with 120 degrees of freedom (Castañeda et al., 2012) and its graphical representation is presented in Figure 1. The model approach is to numerically solve the equations that compose the system with methods developed by DeltaRail through the software VAMPIRE®, where the particular parameters of the model are described in a precedent study (Martinod et al., 2012b). 
Figure 1 Graphic representation of the numerical model of the vehicle (orthogonal view)

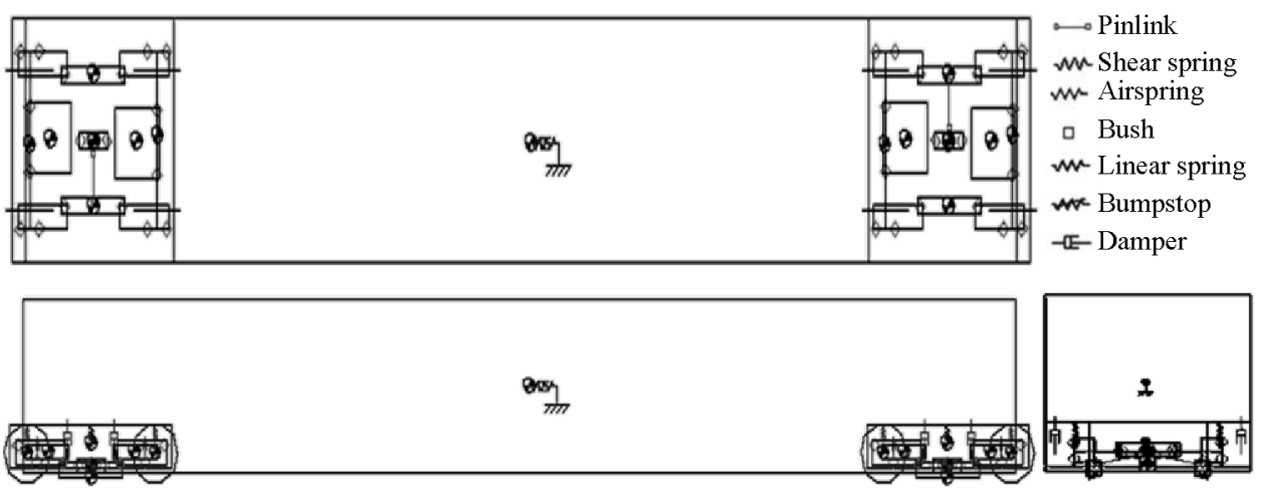

\section{Validation of the numerical model}

The validation process is structured in two stages. In the first stage, two field tests were done using the frontal bolster beam, and a set of measurements of the bolster beam are recorded (Table 3), composed by the acquisition of eight signals - speed, forces and accelerations - distributed in five measuring points (Figure 2). In the second stage, it has been done a set of dynamic simulations of the numerical model that emulates the existing dynamic conditions in the experimental field tests (Appendix 1, Table 6). Then, a direct comparison between the experimental field tests and the numerical tests is performed. The entire dataset is available by from authors of this paper, as an example, Appendix 1 (Figure 7) presents a set of results.

Table 3 Description of the measuring set for the experimental tests

\begin{tabular}{lllcc}
\hline Sensor & Element & Measuring point & Direc. & Name \\
\hline Speed & Axlebox & Train & $X$ & $V$ \\
Uniaxial gauge & Coupling rod Connection with the traction & $X$ & $F 1 L$ \\
& & link & $Y$ & $F 1 T$ \\
Uniaxial gauge & Carbody & Connection to the right damper & $Z$ & $F 5 V$ \\
Uniaxial gauge & Carbody & Connection to the left damper & $Z$ & $F 6 V$ \\
Three-axial & Pivot axis & Centre plate & $X$ & $A 7 L$ \\
accelerometer & & & $Y$ & $A 7 T$ \\
& & & $Z$ & $A 7 V$ \\
\hline
\end{tabular}

The rms value is the estimator used to describe the dynamic signals in time domain; therefore, the difference of the rms values is established as the quantification of the deviation error between the signals, $\varepsilon_{r m s}$. The $\varepsilon_{r m s}$ values have been classified according to the physical nature of the measurement:

- force deviation error, $\mathcal{E}_{F r m s}-$ expressed in load terms

- acceleration deviation error, $\boldsymbol{\varepsilon}_{A r m s}$. 
Figure 2 Location of the measuring points, validation process (orthogonal view) (see online version for colours)

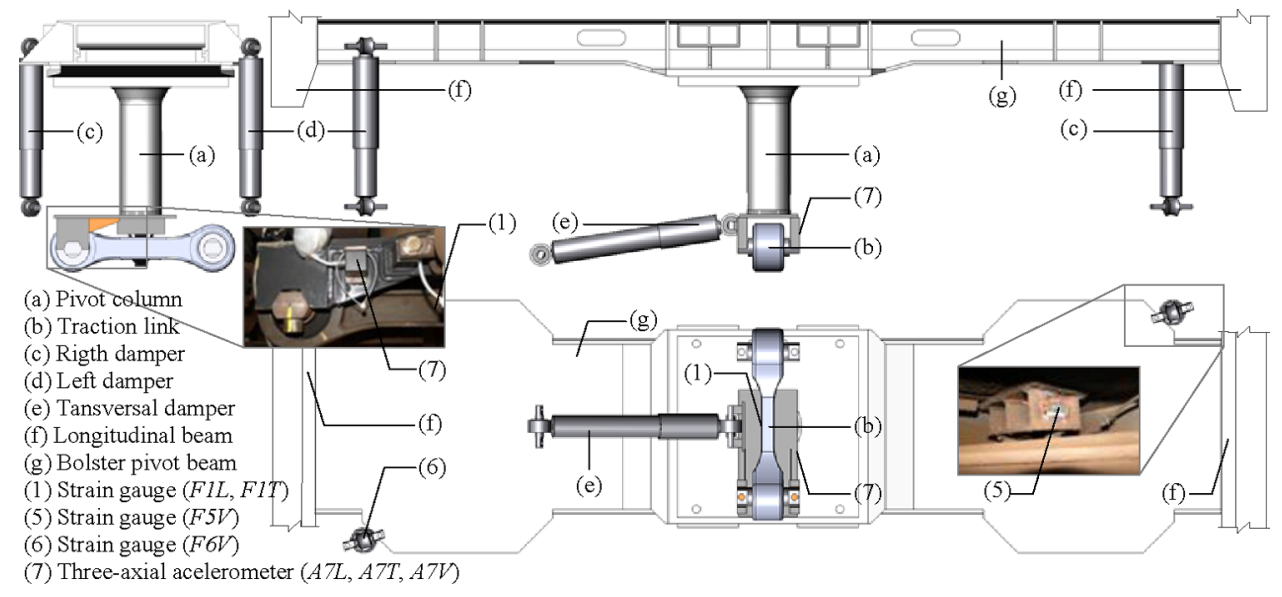

Consequently, it is obtained that $\varepsilon_{r m s}=\left\{\varepsilon_{F r m s}, \varepsilon_{A r m s}\right\}$ represents the precision indicator of the model (Table 4). Considering a limit value of the indicator $\varepsilon_{\text {Frms }}$ equivalent to a 100th fraction of the load carried by the carbody $m_{C B}$, i.e., $\varepsilon_{F l i m}=m_{C B} / 100=236.03 \mathrm{~kg}$, it is observed that $\varepsilon_{F r m s}<<\varepsilon_{\text {Flim }}$. On the other side, considering a limit value of the indicator $\varepsilon_{A r m s}$ equivalent to a 100th part of the gravity constant $1 G$, i.e., $\varepsilon_{\text {Alim }}=1 G / 100=0.098 \mathrm{~m} / \mathrm{s}^{2}$, it is obtained that $\varepsilon_{\text {A rms }}<<\varepsilon_{\text {Alim }}$.

The signals are transformed to the frequency domain; the difference of the peak value between the signals obtained by the experimental and numerical tests represents the error, $\varepsilon_{p S D}$. It is observed that $\varepsilon_{p S D}$ values are found below a $5 \%$ of deviation. It is possible to consider the numerical model valid because the values $\varepsilon=\left\{\varepsilon_{F r m s}, \varepsilon_{A r m s}, \varepsilon_{p S D}\right\}$ represent an acceptable deviation level for the scope of this work.

Table 4 Deviation error between the experimental signals and the numerical simulation, $\varepsilon$

\begin{tabular}{lccccccc}
\hline & \multicolumn{4}{c}{$\varepsilon_{F r m s}[\mathrm{~kg}-\mathrm{f}]$} \\
\cline { 2 - 8 } Tests & $F 1 L$ & $F 1 T$ & $F 5 V$ & $F 6 V$ & $F 7 L$ & $A 7 T$ & $A 7 V$ \\
\hline Test 1 & 133.713 & 11.309 & 81.619 & 09.609 & 0.032 & 0.024 & 0.006 \\
Test 2 & 125.304 & 03.010 & 73.262 & 92.763 & 0.032 & 0.019 & 0.040 \\
\hline
\end{tabular}

\section{Study case}

There are two parameters of curved tracks that generate the major transversal dynamic effect on the vehicle:

- $\quad V$, the running speed of the vehicle on the track

- $s$, the length of the $T C$ section. 
Table 2 allows identifying one track to study: curve $C 44$, with maximum running speed of the vehicle $V=80 \mathrm{~km} / \mathrm{h}$ and a $T C$ section with a shorter length $s_{C 44}=58.96 \mathrm{~m}$.

The focus of the paper is to analyse the effect of the transition curve in the coupling elements between the carbody and the bogie, therefore, it is planned to carry two types of tests to record the load on those coupling elements:

- experimental test in commercial operation conditions

- virtual environment test considering different conditions.

The tests are listed here.

\subsection{Development of the experimental test}

Two experimental tests have been done:

- force-deformation test under laboratory conditions, done on the transversal bumpstop buffer, obtaining the function characterisation of the element stiffness

- field test under commercial operation of the system, in which a vehicle is implemented with a set of transducers with laser distance mounted on the bogie (Figure 3), recording transversal displacement of the pivot column.

Figure 3 Mounting of laser distance transducers
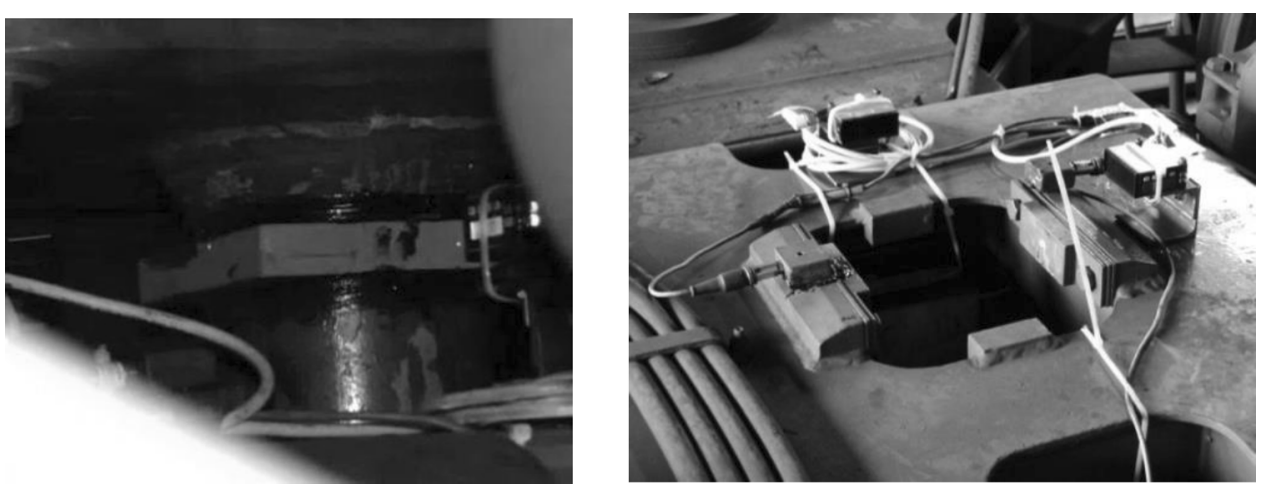

On the basis of the two types of experimental tests

- laboratory

- field, it is possible to find the load exerted on the transversal bumpstop buffers $F 2 T$.

Figure 4 shows the recorded fragment of the results of the obtained dynamic load $F 2 T$ corresponding to the circulation of the vehicle on the track section corresponding to curve $C 44$. It is noted that, on the section track of the transition curve $T_{C f}$, the vehicle speed $V$ is lower than the designed speed track, recording a gradient deceleration. 
Figure 4 Dynamic load $F 2 T$ in circulation of curve $C 44$

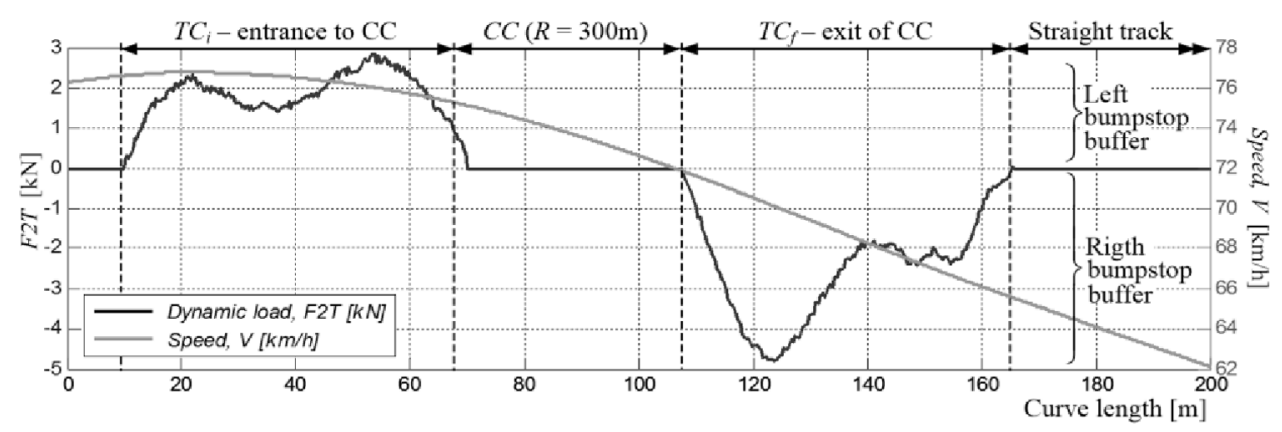

\subsection{Development of the virtual environment test}

The numerical model is used and set to work in different track sections, each one with a different $T C$. Then, a scenario $\xi_{1}$ is defined: a vehicle running in a commercial curved track section corresponding to the curve $C 44(R=300 \mathrm{~m})$ with different running speeds $V=\{40,50,60,70,80,90\} \mathrm{km} / \mathrm{h}$ (see Appendix 2). A numerical model associated to virtual transducers is, therefore, built, located in the secondary suspension stage, and registering the loads that are carried by the pivot column to the transversal bumpstop buffers.

Figure 5 presents the dynamic load $F 2 T$ in the transversal bumpstop buffers during the vehicle circulation in the section track, with different running speed conditions. It is observed that, if the vehicle speed is lower than the designed speed of the track $(V<80 \mathrm{~km} / \mathrm{h})$, the pivot column exerts load over the right bumpstop buffer, i.e., the carbody rests on the path direction - inner side of the curve - owing to a speed deficiency. Table 5 presents the maximum loads over the transversal bumpstop buffers registered in each curved track $\left(T C_{i}, T C_{f}\right)$, noting that, if the vehicle speed is higher, or equal, to the designed speed of the track $(V \geq 80 \mathrm{~km} / \mathrm{h})$, the high value of the component of the clothoid spiral in the transition sections of the curve $\left(T C_{i}, T C_{f}\right)$ generates a dynamic effect between the carbody and the bogie, owing to a considerable twist in the track section. In consequence, it is obtained that:

- $\quad$ the section of the $T C_{i}$ curve causes the pivot column to generate a load over the left bumpstop buffer (the carbody rests on the field track - outer side of the curve)

- the section of the $T C_{f}$ curve causes the pivot column to generate a load over the right bumpstop buffer (the carbody rests on the path direction - inner side of the curve).

The length of the transition sections $\left(T C_{i}, T C_{f}\right)$ of curve $C 44$ causes the Cornu spiral to be considerable; if the twist of the track fails to overcome the rolling inertia of the carbody in circulation on the curve, then the bogie must guide the carbody causing the buffer in the pivot column and load in the transversal bumpstop buffers. 
Figure 5 Dynamic loads $F 2 T$ in curve $C 44$

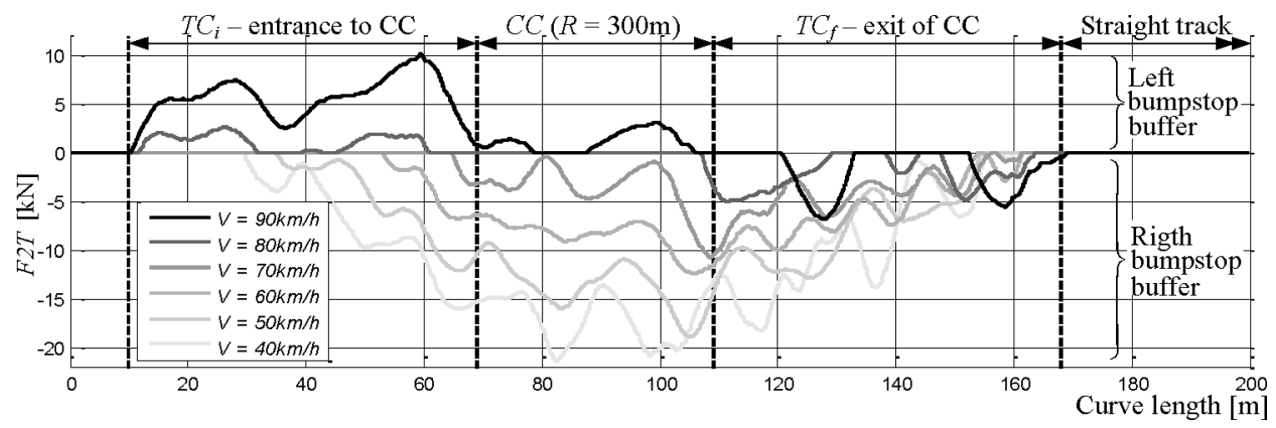

Table $5 \quad \operatorname{Max}(F 2 T)$ values in curve $\mathrm{C} 44$

\begin{tabular}{|c|c|c|c|c|c|c|c|c|}
\hline \multirow[b]{2}{*}{ Load } & \multirow{2}{*}{$\begin{array}{l}\text { Bumpstop } \\
\text { buffer }\end{array}$} & \multirow{2}{*}{$\begin{array}{c}\text { Track } \\
\text { section }\end{array}$} & \multicolumn{6}{|c|}{ Running speed $V[\mathrm{~km} / \mathrm{h}]$} \\
\hline & & & 40 & 50 & 60 & 70 & 80 & 90 \\
\hline \multirow[t]{6}{*}{$\operatorname{Max}(F 2 T)$} & Right & $T C_{i}$ & 16.038 & 12.122 & 6.780 & 3.297 & 0.000 & 0.000 \\
\hline & & $C C$ & 21.337 & 18.877 & 12.391 & 10.726 & 0.000 & 0.001 \\
\hline & & $T C_{f}$ & 18.316 & 14.474 & 11.569 & 10.477 & 4.971 & 6.839 \\
\hline & Left & $T C_{i}$ & 0.000 & 0.000 & 0.000 & 0.000 & 2.634 & 10.185 \\
\hline & & $C C$ & 0.000 & 0.000 & 0.000 & 0.000 & 0.000 & 3.110 \\
\hline & & $T C_{f}$ & 0.000 & 0.000 & 0.000 & 0.000 & 0.000 & 0.007 \\
\hline
\end{tabular}

\section{Analysis of the results}

It is observed that even with the vehicle transiting at designed running speed on short radius curves $(R \approx 300 \mathrm{~m})$, a transversal dynamic effect will exist in the vehicle transitions $\left(T C_{i}, T C_{f}\right)$, such that it carries the bumpstop buffers. As a consequence, it is planned to observe the effect that the length of the $T C$ possesses in relation to the load $F 2 T$, therefore, a scenario $\xi_{2}$ is defined, which constitutes a vehicle at a designed track running speed $V=80 \mathrm{~km} / \mathrm{h}$ circulating in different section curves of short radius ( $R=300 \mathrm{~m}$ ), which differ in the $T C$ length; it is defined as a length of the reference $T C$ section, $s_{C 44}=58.96 \mathrm{~m}$, from which a set of curves is constructed by increasing the parameter, $s=s_{\mathrm{C} 44}+\{+10,+20,+30,+40,+60,+80\} \mathrm{m}$.

Appendix 2 (Figure 8) shows the registers of the $F 2 T$ dynamic load increasing $s$, noting that peak values of the dynamic load in the transversal bumpstop buffers have an inverse relation to the length of the transition curve section, i.e., $\max (F 2 T) \propto s^{-1}$.

From the set of peak values, $\max (F 2 T)$, obtained in the different $s$, it is possible to identify the relation by an exponential regression model (Figure 6).

$$
\begin{aligned}
& \text { for the left bumpstop buffer } \therefore F 2 T(s)=418.85 \mathrm{e}^{-0.085 s}, \\
& \text { for the right bumpstop buffer } \therefore F 2 T(s)=27.128 \mathrm{e}^{-0.027 s,}
\end{aligned}
$$

with a correlation coefficient of $\sqrt{ } R^{2}>0.99$. The regression models are considered valid because the $\sqrt{ } R^{2}$ values represent a measure of association of the statistical model with the obtained data, which have an acceptable level for the scope of the work. 
Figure $6 \operatorname{Max}(F 2 T)$ values increasing the $T C$ length

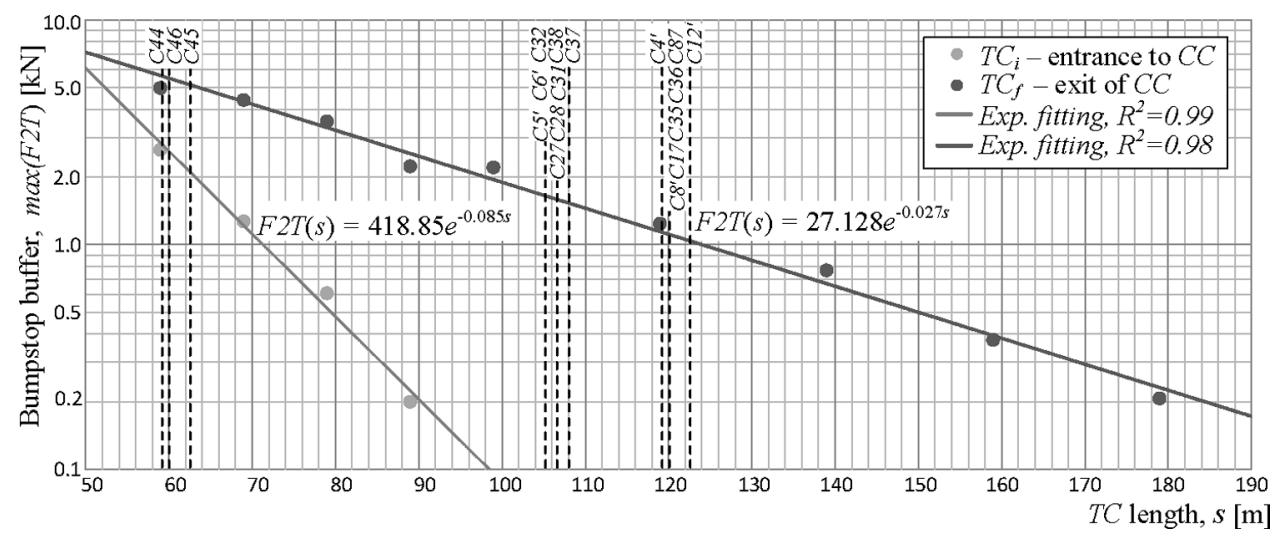

\section{Conclusions and future work}

This work shows a noteworthy utility of the use of virtual techniques that allow generating significant information avoiding unnecessary dead times of the system for inspection.

The paper has proposed and applied a methodology for estimating the effect of the transition curve in the coupling elements between carbody and bogie by measuring variables under commercial conditions of the vehicle.

The vehicle travels at the designed running speed on curved sections with short radius $(R \approx 300 \mathrm{~m})$, which have transition sections $\left(T C_{i}, T C_{f}\right)$ that causes dynamic loads $F 2 T$ in the components:

- the pivot column of the carbody

- the bumpstop buffers of the bogie.

The dynamic loads $F 2 T$ generate cyclic fatigue loads on the pivot column of the carbody and on the bumpstop buffers of the bogie. It is possible to use the exponential regression model obtained in this study, to make modifications to the designed track, specifically in the sections length $T C_{i}$ and $T C_{f}$, mitigating (or even eliminating) the dynamic loads $F 2 T$ that generate fatigue effects on the components.

By the exponential regression model obtained in this study, it is possible to estimate the peak values of the dynamic load, $\max (F 2 T)$, of a comprehensive set of sections tracks with similar section tracks $(R \approx 300 \mathrm{~m}, V=80 \mathrm{~km} / \mathrm{h})$.

In addition, this study can be replicated to find estimations of the dynamic loads exerted on the coupling elements between carbody and bogie for the circulation of the vehicle in track sections with diverse characteristics.

\section{References}

Bruni, S., Vinolas, J., Berg, M., Polach, O. and Stichel, S. (2011) 'Modelling of suspension components in a rail vehicle dynamics context', Vehicle System Dynamics: International Journal of Vehicle Mechanics and Mobility, Vol. 49, No. 7, pp.1021-1072. 
Castañeda, L.F., Betancur, G.R. and Martinod, R.M. (2012) 'Determination of the technical state of suspension elements based on the OMA-LSCE method', Ingegneria Ferroviaria, Vol. 67, No. 1, pp.41-54.

Di Gialleonardo, E., Braghin, F. and Bruni, S. (2012) 'The influence of track modelling options on the simulation of rail vehicle dynamics', Journal of Sound and Vibration, Vol. 331, No. 19, pp. $4246-4258$.

Evans, J. and Berg, M. (2009) 'Challenges in simulation of rail vehicles dynamics', Vehicle System Dynamics: International Journal of Vehicle Mechanics and Mobility, Vol. 47, No. 8, pp.1023-1048.

International Union of Railways (2005) UIC 518: Testing and Approval of Railway Vehicle from the Point of View of Their Dynamic Behaviour - Safety - Track Fatigue - Ride Quality, 3rd ed., France.

Martinod, R.M., Betancur, G.R. and Castañeda, L.F. (2012a) 'Evaluation of the damping elements for two stage suspension vehicles', Ingeniería e Investigación, Vol. 32, No. 1, pp.11-17.

Martinod, R.M., Betancur, G.R. and Castañeda, L.F. (2012b) 'Identification of the technical state of suspension elements in railway systems', Vehicle System Dynamics, Vol. 50, No. 7, pp.1121-1135.

Mundrey, J.S. (2010) Railway Track Engineering, 4th ed., Tata McGraw Hill.

Orlova, A. (2006) 'The anatomy of railway vehicle running gear', Handbook of Railway Vehicle Dynamics, Iwnicki S. (Ed.), CRC Press, USA.

Profillidis, V.A. (2014) Railway Management and Engineering, 4th ed., Ashgate, London.

Shabana, A.A., Zaazaa, K.E. and Sugiyama, H. (2008) Railroad Vehicle Dynamics: A Computational Approach, CRC Press, USA.

Shen, T-I., Chang, C-H., Chang, K-Y. and Lu, C-C. (2013) 'A numerical study of cubic parabolas on railway transition curves', Journal of Marine Science and Technology, Vol. 21, No. 2, pp.191-197.

Spiryagin, M., Cole C., Sun, Y.Q., McClanachan, M., Spiryagin, V. and McSweeney, T. (2014) Design and Simulation of Rail Vehicles, CRC Press, USA.

\section{Appendix 1: Register of the signals from the validation process}

Table 6 Characteristics of the experimental test and numerical simulation

\begin{tabular}{llll}
\hline \multicolumn{2}{l}{ Signals processing } & Experiment & Simulation \\
\hline Data & Sample frequency, $f_{s}[\mathrm{~Hz}]$ & 2400 & 1000 \\
registry & Sample period, $\Delta \mathrm{t}[\mathrm{ms}]$ & 0.4167 & 1.0 \\
\multirow{2}{*}{ Adq. filter } & Type & anti-aliasing & - \\
& Freq. $[\mathrm{Hz}]$ & $1200 \mathrm{~Hz}$ & - \\
\multirow{2}{*}{ Digital filter } & Type & Elliptic & 2-pole Butterworth \\
& & Band-pass & Band-pass \\
& Inferior band $[\mathrm{Hz}]$ & 0.5 & 0.5 \\
& Superior band $[\mathrm{Hz}]$ & 5.0 & 5.0 \\
\hline
\end{tabular}


Figure 7 Signals in time and frequency domain: (a) forces in time domain, $F 5 \mathrm{~V}, F 6 \mathrm{~V}$; (b) traction in time domain, $A 7 T, A 7 V$; (c) braking, $A 7 V, A 7 V$ and (d) traction, $A 7 V, A 7 V$

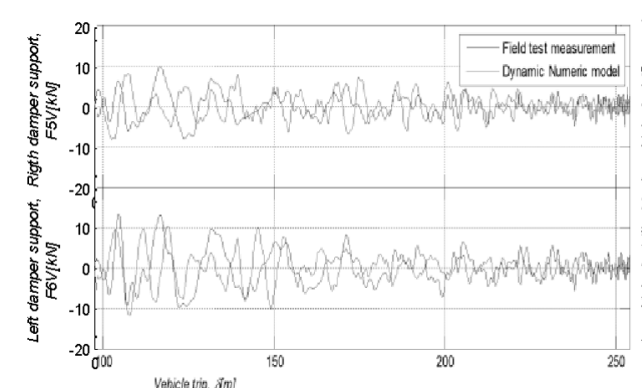

(a)

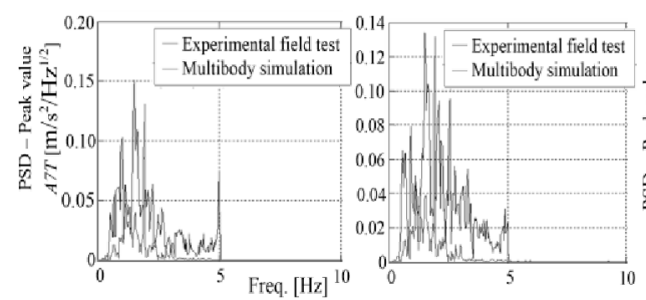

(c)

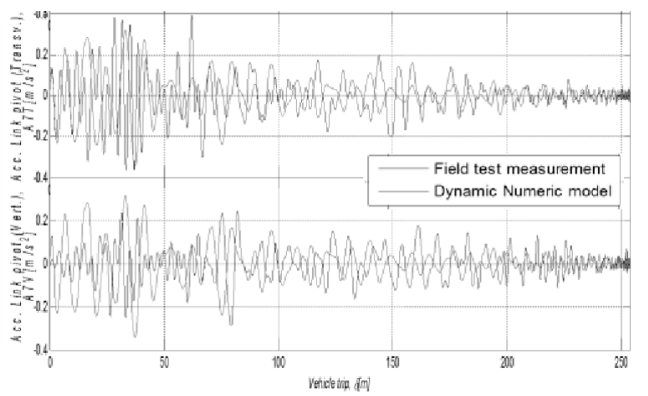

(b)

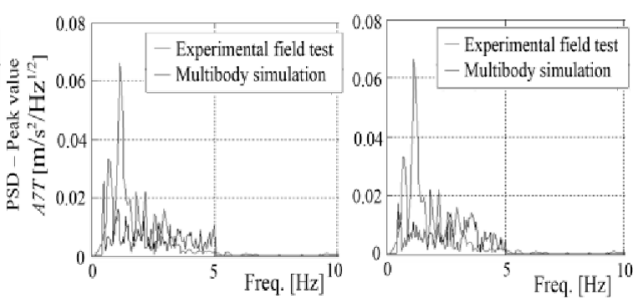

(d)

\section{Appendix 2: Register of the signals of the dynamic load $F 2 T$ increasing the} $T C$ length

Figure 8 Dynamic load $F 2 T$ increasing $s$
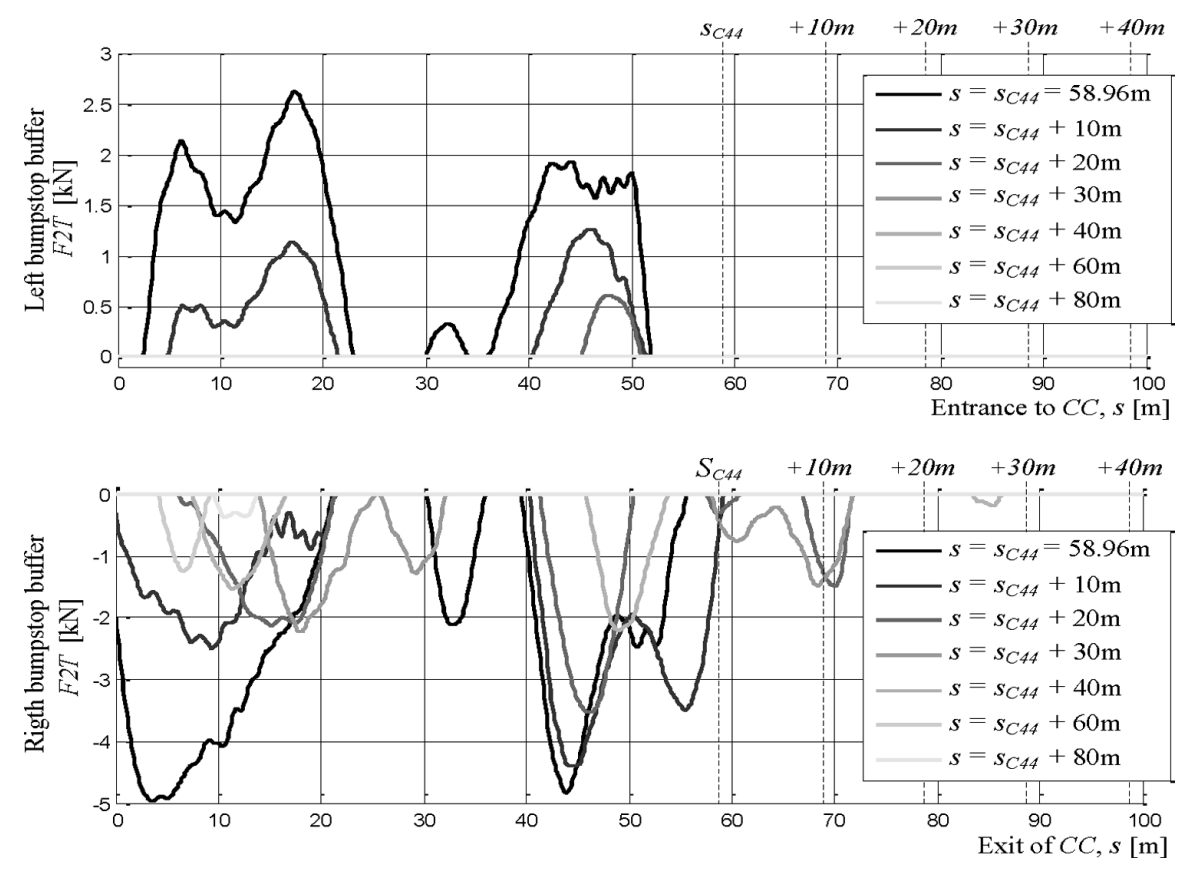